University of Wollongong

Research Online

Australian Institute for Innovative Materials -

Papers

Australian Institute for Innovative Materials

$1-1-2013$

Extrusion printing of ionic-covalent entanglement hydrogels with high toughness

Shannon Bakarich

University of Wollongong, seb798@uowmail.edu.au

Marc in het Panhuis

University of Wollongong, panhuis@uow.edu.au

Stephen T. Beirne

University of Wollongong, sbeirne@uow.edu.au

Gordon G. Wallace

University of Wollongong, gwallace@uow.edu.au

Geoffrey Maxwell Spinks

University of Wollongong, gspinks@uow.edu.au

Follow this and additional works at: https://ro.uow.edu.au/aiimpapers

Part of the Engineering Commons, and the Physical Sciences and Mathematics Commons

Research Online is the open access institutional repository for the University of Wollongong. For further information contact the UOW Library: research-pubs@uow.edu.au 


\title{
Extrusion printing of ionic-covalent entanglement hydrogels with high toughness
}

\begin{abstract}
Three-dimensional (3D) printing of hydrogels has recently been investigated for use in tissue engineering applications. One major limitation in the use of synthetic hydrogels is their poor mechanical robustness but the development of 'tough hydrogels' in conjunction with additive fabrication techniques will accelerate the advancement of many technologies including soft robotics, bionic implants, sensors and controlled release systems. This article demonstrates that ionic-covalent entanglement (ICE) gels can be fabricated through a modified extrusion printing process that facilitates in situ photopolymerisation. The rheological properties of alginate-acrylamide hydrogel precursor solutions were characterised to develop formulations suitable for extrusion printing. A range of these printed hydrogels were prepared and their mechanical performance and swelling behaviour evaluated. ICE gels exhibit a remarkable mechanical performance because ionic cross links in the biopolymer network act as sacrificial bonds that dissipate energy under stress. The printed ICE gels have a work of extension $2603 \mathrm{kj} \mathrm{m3}$. Swelling the hydrogels in water has a detrimental effect upon their mechanical properties, however swelling the hydrogels in a calcium chloride solution as a post-processing technique reduces the effects of swelling the hydrogels in water. The integration of the modified extrusion printing process with existing plastic 3D printing technologies will allow for the fabrication of functional devices.
\end{abstract}

\section{Keywords}

printing, hydrogels, entanglement, extrusion, covalent, toughness, ionic, high

Disciplines

Engineering | Physical Sciences and Mathematics

\section{Publication Details}

Bakarich, S., in het Panhuis, M., Beirne, S. T., Wallace, G. G. and Spinks, G. Maxwell. (2013). Extrusion printing of ionic-covalent entanglement hydrogels with high toughness. Journal of Materials Chemistry $B$, 1 (38), 4939-4946. 


\title{
Extrusion printing of ionic-covalent entanglement hydrogels with high toughness
}

\author{
Shannon E. Bakarich, ${ }^{a, b}$ Marc in het Panhuis, ${ }^{a, c}$ Stephen Beirne, ${ }^{a}$ Gordon G. Wallace ${ }^{a}$ and Geoffrey M. \\ Spinks*a,b
}

\author{
5 Received (in $X X X, X X X) X$ th $X X X X X X X X X 20 X X$, Accepted Xth XXXXXXXXX 20XX \\ DOI: 10.1039/b000000x
}

Three-dimensional (3D) printing of hydrogels has recently been investigated for use in tissue engineering applications. One major limitation in the use of synthetic hydrogels is their poor mechanical robustness but the development of 'tough hydrogels' in conjunction with additive fabrication techniques will 10 accelerate the advancement of many technologies including soft robotics, bionic implants, sensors and controlled release systems. This article demonstrates that ionic-covalent entanglement (ICE) gels can be fabricated through a modified extrusion printing process that facilitates in situ photopolymerisation. The rheological properties of alginate/acrylamide hydrogel precursor solutions were characterised to develop formulations suitable for extrusion printing. A range of these printed hydrogels were prepared and their

15 mechanical performance and swelling behaviour evaluated. ICE gels exhibit a remarkable mechanical performance because ionic cross links in the biopolymer network act as sacrificial bonds that dissipate energy under stress. The printed ICE gels have a work of extension $260 \pm 3 \mathrm{~kJ} / \mathrm{m}^{3}$. Swelling the hydrogels in water has a detrimental effect upon their mechanical properties, however swelling the hydrogels in a calcium chloride solution as a post-processing technique reduces the effects of swelling the hydrogels in

20 water. The integration of the modified extrusion printing process with existing plastic 3D printing technologies will allow for the fabrication of functional devices.

\section{Introduction}

Additive fabrication techniques such as three-dimensional (3D) ${ }_{25}$ printing are receiving growing interest from a diverse range of fields due to their ability to quickly produce complex 3D objects. ${ }^{1}$ One of the exciting features of the additive fabrication process is the capacity of some systems to print multiple materials within a single component. This capability gives the operator 3D control 30 over material properties within an object by positioning and blending materials. ${ }^{2-3}$ Utilising additive fabrication, controlled variations in material properties of an object can be exploited within a device as functionality. For example, the introduction of electrically conducting materials in polymer-based objects can 35 introduce electronic functionality. Sensing and actuating materials can provide additional utility. The parallel development of such materials and suitable 3D fabrication techniques will accelerate the advancement of many technologies including soft robotics, bionic implants, sensors and controlled release systems.

40 Recently, 3D printing of hydrogels has been investigated for tissue engineering applications..$^{4-7}$ Hydrogels are hydrophilic polymer networks capable of retaining large volumes of water in common with much soft biological tissue. When printing these materials a hydrogel precursor solution is patterned into a defined 45 shape that is subsequently fixed by gelation. Dependent on viscosity, the precursor solution can be patterned by either inkjet or extrusion. ${ }^{7}$ The gelation is typically a cross linking reaction initiated by light, by a chemical or by a thermal transition. ${ }^{8}$ Using this process hydrogels have been fabricated into cell scaffolds, ${ }^{9}$ 50 and, more recently, as pseudo tissues ${ }^{10}$.

One major limitation in the use of synthetic hydrogels is their poor mechanical robustness, although recently a number of toughened hydrogels have been reported ${ }^{11}$. The new materials have been designed with a variety of toughening mechanisms that 55 increase the energy dissipation during crack propagation. Examples of these tough hydrogels include slip-link gels, ${ }^{12}$ nanocomposite gels, ${ }^{13}$ double-network gels ${ }^{14}$ and ionic-covalent entanglement gels. ${ }^{15-16}$ Toughened hydrogels have fracture energies in the range of $1000 \mathrm{~J} / \mathrm{m}^{2}$ compared with values less 10 ${ }_{60} \mathrm{~J} / \mathrm{m}^{2}$ for conventional hydrogels. ${ }^{11}$ The synthesis of these new materials requires complex and in some cases multi-step chemical reactions. Until now toughened hydrogels have not been considered compatible for processing through additive fabrication techniques because of their complex synthesis.

65 The combination of additive fabrication techniques with tough hydrogels will be a significant advance in the application of these 
materials. The aim of the present study was to determine whether ionic-covalent entanglement (ICE) gels could be prepared by extrusion printing and retain their high toughness. Ionic-covalent entanglement gels are a special case of interpenetrating polymer 5 network gel that exhibit a remarkable mechanical performance and that can be synthesised in a relatively straightforward simultaneous network formation process. ${ }^{15}$ Alginatepolyacrylamide ICE gels reported by Sun et al. ${ }^{17}$ have a reported fracture energy $\sim 9000 \mathrm{~J} / \mathrm{m}^{2}$.

10 In this paper ICE gels were fabricated with a UV printing technique that was designed for printing interpenetrating polymer networks. ${ }^{18}$ A hydrogel precursor solution ink containing alginate biopolymer and acrylamide monomer was patterned by extrusion printing and cured in situ by a UV light source.

\section{${ }_{15}$ Experimental}

\section{Materials}

All materials were used as received and all solutions were prepared using Milli-Q water (resistivity $=18.2 \Omega \mathrm{cm}$ ). Acrylamide (Amm) monomer and $\alpha$-keto glutaric acid photo20 initiator were purchased from Fluka (Australia). Alginic acid sodium salt, from brown algae with Brookfield viscosity (2\% in $\mathrm{H}_{2} \mathrm{O}$ at $25{ }^{0} \mathrm{C}$ ) of $250 \mathrm{mPas}$, N,N'-methylenebisacrylamide, calcium chloride (minimum 93.0\% granular anhydrous) cross linkers and ethylene glycol rheology modifier were purchased 25 from Sigma Aldrich (Australia). Microscope slides (Sail Brand, Cat.No. 7101) were used as received.

\section{Ink Formulation}

The alginate/acrylamide ink was produced by adding alganic sodium salt to a stock solution of UV-curable acrylamide. The 30 acrylamide solution was prepared by dissolving $6 \mathrm{~g}$ of acrylamide, $129 \mathrm{mg}$ of N,N'-methylenebisacrylamide and $123 \mathrm{mg}$ of $\alpha$-keto glutaric acid in $26.5 \mathrm{ml}$ of Milli-Q water, $5 \mathrm{ml}$ of the $0.1 \mathrm{M}$ calcium chloride stock solution and $12.5 \mathrm{ml}$ of ethylene glycol. The latter was used as a non-volatile co-solvent with the 35 ratio of ethylene glycol to water fixed at 1:2.5... Alganic sodium salt was stirred into the acrylamide solution with a spatula. Alginate/acrylamide inks were produced with fixed amounts of acrylamide and varying alginate concentrations $1 \%$ and $5 \%$ (w/v). For each $1 \mathrm{ml}$ of ink $10 \mathrm{mg}$ of alganic salt was added to 1 $40 \mathrm{ml}$ of acrylamide solution for every $1 \%(\mathrm{w} / \mathrm{v})$ of alginate. The weight ratio of Amm to Amm and alginate varied from $70 \%$ to $92 \%$ as the alginate concentration decreased from $5 \%$ to $1 \%$ $(\mathrm{w} / \mathrm{v})$.

\section{Rheology}

45 The flow behaviour of the alginate/acryamide inks was determined using a AR2G Rheometer coupled with a cone and plate measuring system (diameter $40 \mathrm{~mm}$, angle $2^{0} 06^{\circ}$ and truncation $55 \mu \mathrm{m}$ ) and a heat controlled sample stage (TA instruments peltier plate). The viscosity was measured as a 50 function of shear rate $(1-5001 / \mathrm{s})$. Measurements were performed on inks at $25{ }^{\circ} \mathrm{C}$ and $35{ }^{\circ} \mathrm{C}$.

\section{Extrusion Printing}

A KIMM SPS1000 Bioplotter extrusion system (Korea Institute of Machinery and Material) in conjunction with a UV-curing
55 system was used to print hydrogel structures from the alginate/acryamide inks. The Dymax BlueWave 75 Rev 2.0 UV Light Curing Spot Lamp System using a 19+ W/ $\mathrm{cm}^{2}$ UV source with a 1 meter light guide was used to cure the printed ink. The end of the light guide was fixed to the print head $50 \mathrm{~mm}$ away

${ }_{60}$ from the nozzle by a custom-build brace (designed in SolidWorks and printed using a Dimension uPrint Plus).

Computer-aided design (SolidWorks) was used to construct a digital model of the item to be printed. Proprietary KIMM software was used to transform the digital model into a set of 65 numerical commands that determine the printing path. This command file was then edited to accommodate for the UVcuring system. The UV light was passed over each complete layer of ink once (90 s) and over the final layer a further three times (270 s) at a height of $25 \mathrm{~mm}$. UV polymerization proceeded in air 70 and future printer designs may provide an inert atmosphere to limit oxygen inhibition.

The alginate/acryamide ink was loaded into a pressurised stainless steel barrel in a temperature controlled jacket. A 23 gauge extrusion nozzle (diameter $0.337 \mathrm{~mm}$ ) was fitted to the end 75 of the barrel. The barrel temperature was held stable during printing at either $25{ }^{\circ} \mathrm{C}$ or $35{ }^{\circ} \mathrm{C}$. The printing pressure $(30-130$ $\mathrm{kPa}$ ) was optimised for each ink to deliver repeatable, unbroken and unblotted lines. The alginate/acryamide ink was printed onto an untreated glass slide. The printed samples were stored in 80 silicone oil prior to characterisation.

\section{Mechanical testing}

The mechanical properties of the printed hydrogels were determined using a Shimadzu EZ-L Universal Mechanical Tester. Tensile tests were performed using a $10 \mathrm{~N}$ load cell and spring ${ }_{85}$ loaded clamps. Printed dog bone samples were strained to failure at a rate of $10 \mathrm{~mm} / \mathrm{min}$. The applied stress was calculated using the total average cross sectional area of the gauge length. The Work of Extension was calculated as the area under the stressstrain curve.

\section{Swelling}

The swelling ratio was determined after immersing printed hydrogels samples in Milli-Q water for $72 \mathrm{hr}$ or in $0.1 \mathrm{M}$ aqueous calcium chloride for $72 \mathrm{hr}$. Swelling was also determined for samples immersed first in $0.1 \mathrm{M}$ calcium chloride $(72 \mathrm{hr}$ ) followed 95 by Milli-Q water $(72 \mathrm{hr})$. Swelling ratios ${ }^{19} Q$ were calculated using:

$$
Q=\frac{W_{f}}{W_{i}} \times 100 \%
$$

where $W_{i}$ is the initial weight of hydrogel before swelling and $W_{f}$ is the final mass of the hydrogel after swelling. Samples were 100 dried by being placed in an oven at $60{ }^{\circ} \mathrm{C}$ for $72 \mathrm{hr}$.

\section{Thermal Gravimetric Analysis}

Thermal gravimetric analysis was conducted on hydrogel samples with the TA instruments Q500 Thermal Gravimetric Analyser. The hydrogels were heated from $25{ }^{\circ} \mathrm{C}$ to $600{ }^{\circ} \mathrm{C}$ at a 105 rate $5{ }^{0} \mathrm{C} / \mathrm{min}$. The furnace was filled with a flow of air at a rate $90 \mathrm{ml} / \mathrm{min}$ and nitrogen at a rate $10 \mathrm{ml} / \mathrm{min}$. 

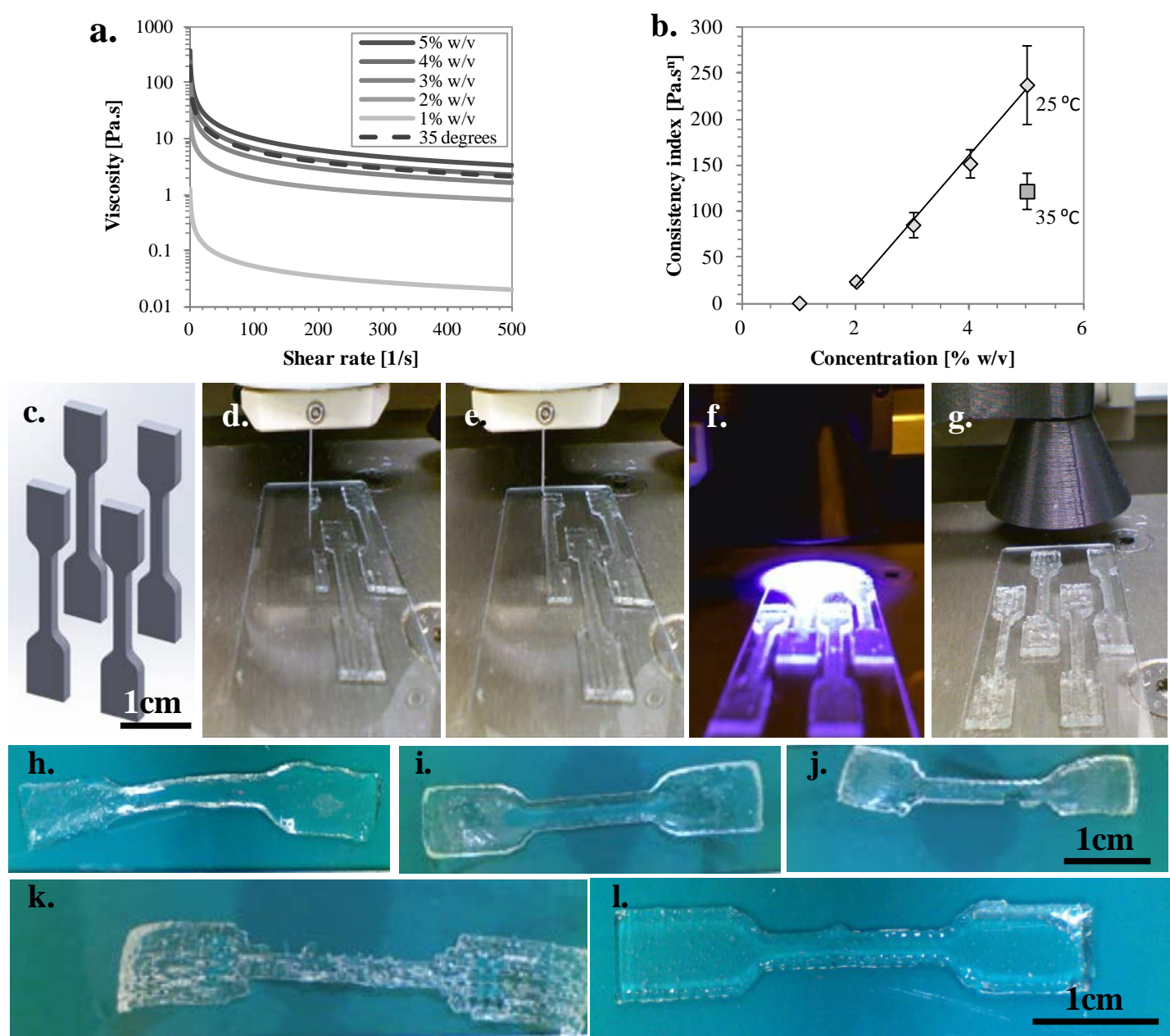

Fig. 1 a. Flow curves of $1,2,3,4$ and $5 \% \mathrm{w} / \mathrm{v}$ alginate hydrogel precursor solutions at $25^{\circ} \mathrm{C}$ and $5 \% \mathrm{w} / \mathrm{v}$ alginate printing solution at $35{ }^{\circ} \mathrm{C}$. b. A plot of the hydrogel precursor solution consistency index against alginate concentration showing the linear relationship between consistency and concentration above $2 \% \mathrm{w} / \mathrm{v}$. c. CAD model of 4 dog bone specimens. d-e. Patterning of hydrogel filaments to produce dog bone specimens. f. The custom UV 5 attachment used to cure the patterned hydrogel ink. g. Completed hydrogel dog-bone specimens. Photographs of alginate/PAAm ICE hydrogel dog bone specimens printed with $2,3,4$ and $5 \% \mathrm{w} / \mathrm{v}$ alginate solutions $\left(\mathrm{h}, \mathrm{i}, \mathrm{j}\right.$ and $\mathrm{k}$ respectively) printed at $25^{\circ} \mathrm{C}$. I. An alginate/PAAm ICE hydrogel dog bone specimen printed from the $5 \% \mathrm{w} / \mathrm{v}$ alginate solution at $35^{\circ} \mathrm{C}$

Table 1 Summary of the rheological parameters measured for the ICE gel inks. Consistency $(K)$ and power law $(n)$ indices were obtained through 10 curve fitting with equation 2.

\begin{tabular}{cccc}
\hline $\begin{array}{c}\text { Alginate } \\
\text { Concentration } \\
{[\% \mathrm{w} / \mathrm{v}]}\end{array}$ & $\begin{array}{c}\text { Print Temperature } \\
{\left[{ }^{\circ} \mathrm{C}\right]}\end{array}$ & $\begin{array}{c}K \\
{\left[\text { Pa. }^{\mathrm{n}}\right]}\end{array}$ & $n$ \\
\hline 1 & 25 & $0.81 \pm 0.20$ & $0.40 \pm 0.04$ \\
2 & 25 & $24 \pm 3.0$ & $0.45 \pm 0.01$ \\
3 & 25 & $86 \pm 10$ & $0.37 \pm 0.01$ \\
4 & 25 & $152 \pm 20$ & $0.33 \pm 0.01$ \\
5 & 25 & $238 \pm 40$ & $0.32 \pm 0.01$ \\
5 & 35 & $122 \pm 20$ & $0.35 \pm 0.03$ \\
\hline
\end{tabular}

\section{Results}

This study aimed to determine whether 3D extrusion printing could be used to produce tough hydrogels formed from an ionic covalent entanglement gel system. Firstly, the pre-gel printing

15 inks were formulated to meet the rheological requirements for extrusion printing. Using these rheological acceptable formulations, a simple dumbbell shape was printed and cured with UV radiation to both demonstrate printability and to measure mechanical properties.

\section{${ }_{20}$ Extrusion printing}

Viscosity $(\eta)$ measurements of the alginate/acrylamide printing inks were evaluated to determine their suitability for extrusion printing. The resulting flow curves (Figure 1a) were fitted to a power law model ${ }^{20}$ :

$$
\eta=K \dot{\gamma}^{n-1},
$$

where $\dot{\gamma}$ is the shear rate, $K$ is the consistency index, and $n$ is the power law index. The printing solutions exhibit pseudoplastic (non-Newtownian) shear-thinning flow behaviour typical of polymer solutions $(n<1)$. As the alginate concentration 30 increased the solutions were found to become more shear thinning ( $n$ decreases), and much thicker ( $K$ increases), see Table 1. The consistency index was found to be linearly proportional to concentration for concentrations between $2 \% \mathrm{w} / \mathrm{v}$ and $5 \% \mathrm{w} / \mathrm{v}$ (Figure 1b). The large difference in consistency between $1 \% \mathrm{w} / \mathrm{v}$ 35 and $2 \% \mathrm{w} / \mathrm{v}$ alginate solutions could suggest that the dilute to 
Table 2 Summary of the mechanical properties of printed ICE gels with various weight ratios of acrylamide to (acrylamide plus alginate). All gels were printed with the same amount of acrylamide and with varying alginate concentrations.

\begin{tabular}{cccccc}
\hline $\begin{array}{c}\text { Amm/(Amm+alginate) } \\
{[\% \mathrm{w} / \mathrm{w}]}\end{array}$ & $\begin{array}{c}\text { Print Temperature } \\
{\left[{ }^{\circ} \mathrm{C}\right]}\end{array}$ & $\begin{array}{c}\text { Young's Modulus } \\
{[\mathrm{kPa}]}\end{array}$ & $\begin{array}{c}\text { Failure Stress } \\
{[\mathrm{kPa}]}\end{array}$ & $\begin{array}{c}\text { Failure Strain } \\
{[\%]}\end{array}$ & $\begin{array}{c}\text { Work of Extension } \\
{\left[\mathrm{kJ} / \mathrm{m}^{3}\right]}\end{array}$ \\
\hline 85 & 25 & $48 \pm 3$ & $91 \pm 30$ & $210 \pm 70$ & $95 \pm 10$ \\
80 & 25 & $66 \pm 5$ & $170 \pm 30$ & $300 \pm 20$ & $260 \pm 4$ \\
75 & 25 & $78 \pm 10$ & $110 \pm 50$ & $150 \pm 70$ & $83 \pm 20$ \\
70 & 25 & $61 \pm 6$ & $130 \pm 10$ & $90 \pm 5$ & $59 \pm 1$ \\
70 & 35 & $83 \pm 10$ & $140 \pm 20$ & $220 \pm 10$ & $154 \pm 1$ \\
\hline
\end{tabular}

semi-dilute transition is somewhere in this concentration range. It was not possible to extrusion print the alginate solutions with 5 concentrations below $2 \% \mathrm{w} / \mathrm{v}$ due to insufficient viscosity (low consistency) that led to unacceptable sagging and spreading of the extrudate. Alginate solutions with concentration above $2 \%$ $\mathrm{w} / \mathrm{v}$ were found to possess flow characteristics compatible with the processable range of our extrusion printing system.

10 ICE hydrogels were produced using a modified commerciallyavailable extrusion printer. The printer was modified by mounting a fibre-optic light guide to the print head.

Alginate/acrylamide hydrogels were fabricated using the adapted extrusion printing process. Figure 1c-g illustrates the fabrication 15 of dog-bone specimens for tensile testing. The resolution of the printed hydrogels improved as the consistency of the ink increased. In the computer model the reduced section of the dogbone specimens was $2 \mathrm{~mm}$ in width. The reduced section of 4 separate hydrogel samples printed with the $2 \% \mathrm{w} / \mathrm{v}$ alginate 20 solution (Figure $1 \mathrm{~h}$ ) was $2.3 \pm 0.2 \mathrm{~mm}$ wide compared to the reduced section of dog-bones printed with the $4 \% \mathrm{w} / \mathrm{v}$ alginate solution (Figure 1j) which was $1.9 \pm 0.1 \mathrm{~mm}$ wide. Printed ink can flow and deform from its patterned shape until the shape is fixed by the cross linking reaction induced by UV light. The 25 thicker (more viscous) ink deforms more slowly giving improved resolution to the final structure.

The printer produces shapes by patterning ink fibres spaced 0.3 $\mathrm{mm}$ apart. A solid structure is formed when these fibres sag and spread to make contact with neighbouring fibres so that the ink 30 fuses together. At $25{ }^{0} \mathrm{C}$ the flow behaviour of the fibres produced by the solution containing $5 \% \mathrm{w} / \mathrm{v}$ alginate was too high for the fibres to combine in the time prior to UV-curing. Consequently, the hydrogel structures produced by the $5 \% \mathrm{w} / \mathrm{v}$ alginate solution were highly porous with voids left between the 35 defined fibres (Figure $1 \mathrm{k}$ ). The flow behaviour of the $5 \% \mathrm{w} / \mathrm{v}$ alginate solution was improved by heating to $35{ }^{\circ} \mathrm{C}$, resulting in a significant reduction in consistency (Table 1 ). The flow characteristics of the $5 \% \mathrm{w} / \mathrm{v}$ solution at $35{ }^{\circ} \mathrm{C}$ are similar to that of a $3.5 \%$ solution at $25{ }^{\circ} \mathrm{C}$, which is calculated using the linear 40 relationship between consistency and alginate concentration. The resulting improved flow characteristics facilitated the formation of solid, non-porous structures from the printed fibres (Figure 1l).

\section{Tensile Testing of As-Printed Hydrogels}

To determine the prospects of printed alginate/acrylamide 45 hydrogels in load bearing applications the printed dog bone specimens were mechanically characterised in tension. Examples of typical stress - strain curves for the printed hydrogels are included in Figure 2a and a summary of the alginate/acrylamide hydrogel mechanical properties are shown in Table 2. The tensile so strength, Young's modulus and failure strain are considerably
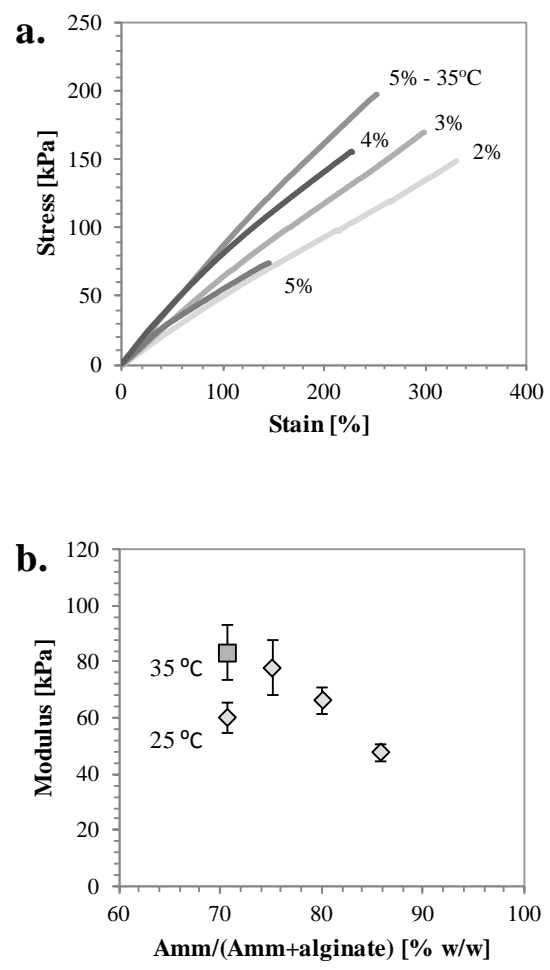

Fig 2 a. Typical tensile stress strain curves of printed ICE hydrogels. b. The effect of weight ratio of acrylamide to (acrylamide plus alginate), on 55 the modulus of ICE hydrogels printed at $25{ }^{\circ} \mathrm{C}$ (diamonds) and at $35^{\circ} \mathrm{C}$

(squares). All samples were printed with the same polyacrylamide content but with different concentrations of alginate: $2 \%, 3 \%, 4 \%$ and $5 \%$ corresponding to $85 \%, 80 \%, 75 \%$ and $70 \% \mathrm{Amm} /(\mathrm{Amm}+$ alginate) weight ratios.

${ }_{60}$ lower in hydrogels printed with $5 \% \mathrm{w} / \mathrm{v}$ alginate ink at $25{ }^{\circ} \mathrm{C}$ in comparison to the samples of the same formulation printed at 35 ${ }^{0} \mathrm{C}$. The highly porous nature of the incompletely-fused samples prepared at $25{ }^{0} \mathrm{C}$ can account for the reduced mechanical properties. Both the Young's modulus and failure stress are 65 reduced since the real cross sectional area of the samples is smaller than the cross sectional area of the printed structure. Additionally, voids in the hydrogels act like flaws which dramatically lower the failure stress and failure strain of the printed structures.

70 The Young's modulus of the non-porous hydrogels increased as the alginate concentration was increased (Figure 2b). The ionically cross linked alginate forms a tighter network than the covalently cross linked acrylamide network. Consequently, increasing the proportion of alginate to acrylamide increases the 


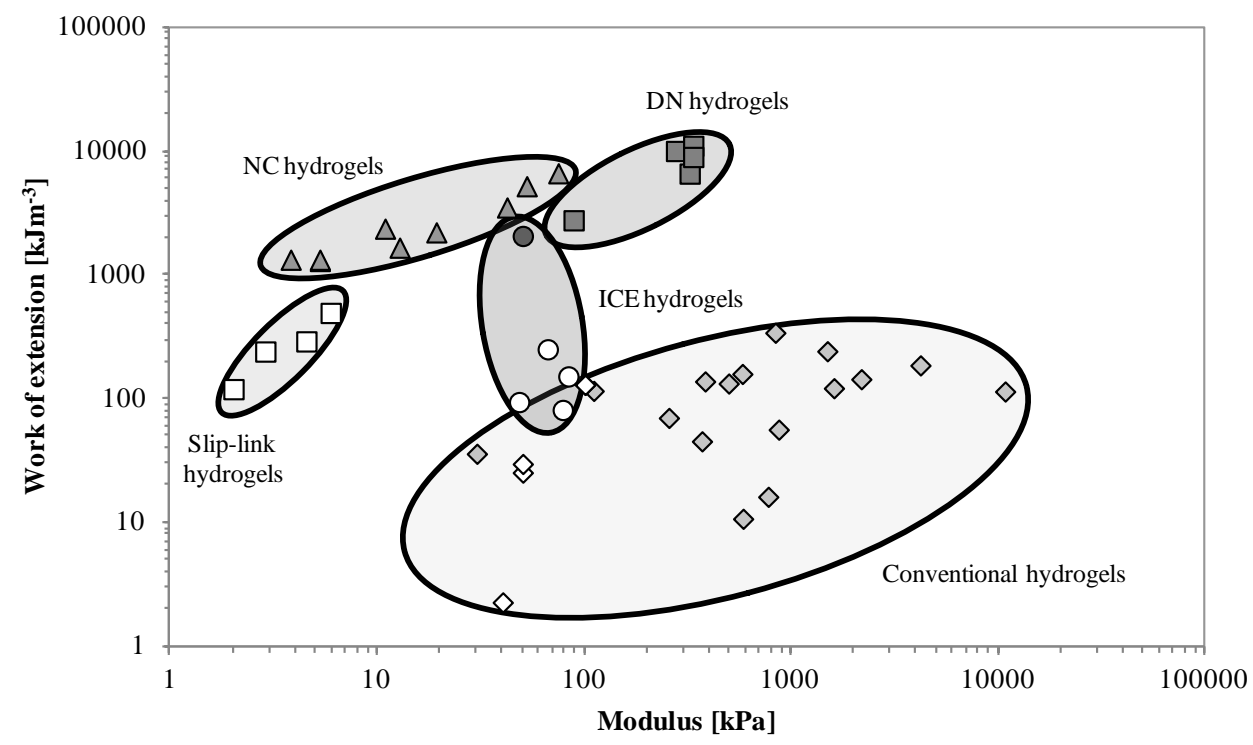

Fig. 3 A comparison of the work of extension values for the printed ICE hydrogels (open circles - this work), cast ICE hydrogels ${ }^{17}$ (filled circles), single network hydrogels (including hydrophilic homopolymers - open diamonds and copolymers using hydrophobic co-monomer - filled diamonds), double network hydrogels (filled squares), nanocomposite hydrogels (triangles) and slip-link hydrogels (open squares), adapted from ${ }^{11}$.

5 average cross link density and, in turn, increases modulus. The effect of alginate content on failure stress and strain was less significant with comparisons made difficult by the high degree of variability in these properties. Random voids introduced by air bubbles or clogging during extrusion likely introduced defects 10 that influenced the failure stress and strain.

A comparison of mechanical properties shows that the printed ICE hydrogels have a smaller work of extension than the ICE hydrogels fabricated by casting by Sun et al. ${ }^{17}$ (Figure 3). For example, the hydrogels printed from the $3 \% \mathrm{w} / \mathrm{v}$ alginate solution 15 have an acrylamide to acrylamide and alginate ratio of $80 \% \mathrm{w} / \mathrm{w}$. The failure stress and failure strain of these printed hydrogels are $170 \pm 30 \mathrm{kPa}$ and $300 \pm 20 \%$, respectively. The corresponding failure stress and failure strain for an equivalent manually fabricated hydrogel were $\sim 220 \mathrm{kPa}^{17}$ and $\sim 900 \%{ }^{17}$ 20 respectively. The introduction of structural flaws inthe hydrogel from the printing process has a significant detrimental effect on the failure strain. Although the mechanical performance of the printed ICE hydrogels is inferior to that of the manually fabricated ICE hydrogels the printed alginate/acrylamide 25 hydrogels have a superior mechanical performance compared with other printed alginate structures. For instance the hydrogels printed from the $2 \% \mathrm{w} / \mathrm{v}$ alginate solution have a tensile strength $91 \pm 30 \mathrm{kPa}$ compared to a tensile strength of $44 \pm 10 \mathrm{kPa}$ for hydrogels printed from a $2.3 \%$ alginate and $0.1 \%$ gelatine so solution used for bio-engineered cardiac pseudo tissue applications. ${ }^{10}$

\section{Swelling Behaviour and Mechanical Properties of Fully- Swollen Hydrogels}

The material properties of hydrogels and their size / shape are 35 dependent upon their water content which is influenced by their ambient environment. Printed hydrogels are likely to be used fully immersed in aqueous solutions, so it is important to characterise the extent of swelling that occurs post-printing. In
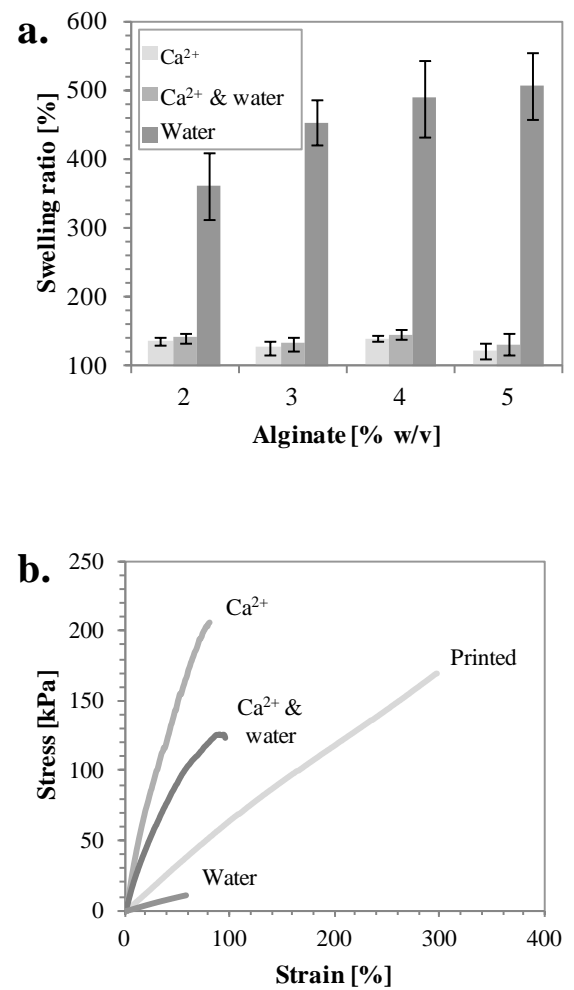

Fig. 4 a. Mass swelling ratio of as made hydrogels printed with 2, 3, 4 and $5 \% \mathrm{w} / \mathrm{v}$ alginate solutions swollen in water, $0.1 \mathrm{M}$ calcium chloride solution and in calcium chloride and then swollen in water. b. Typical tensile stress strain curves of swollen ICE hydrogels.

45 this study, the printed hydrogels were swollen in water or in 0.1 $\mathrm{M}$ calcium chloride solution or in water following the calcium chloride treatment. The mass swelling ratio of the equilibrated 
Table 3 Summary of the mechanical properties of hydrogels printed from the 3\% w/v alginate solution when swollen in water, $0.1 \mathrm{M}$ calcium chloride solution and $0.1 \mathrm{M}$ calcium chloride solution followed by water.

\begin{tabular}{|c|c|c|c|c|}
\hline & $\begin{array}{c}\text { Young's Modulus } \\
{[\mathrm{kPa}]}\end{array}$ & $\begin{array}{c}\text { Failure Stress } \\
{[\mathrm{kPa}]}\end{array}$ & $\begin{array}{c}\text { Failure Strain } \\
{[\%]}\end{array}$ & $\begin{array}{c}\text { Work of Extension } \\
{\left[\mathrm{kJ} / \mathrm{m}^{3}\right]}\end{array}$ \\
\hline As Made & $67 \pm 5$ & $170 \pm 30$ & $300 \pm 20$ & $260 \pm 3$ \\
\hline Water & $23 \pm 3$ & $11 \pm 3$ & $23 \pm 6$ & $1.2 \pm 0.1$ \\
\hline $\mathrm{Ca}^{2+}$ & $370 \pm 20$ & $200 \pm 20$ & $89 \pm 20$ & $89 \pm 2$ \\
\hline $\mathrm{Ca}^{2+} \&$ Water & $260 \pm 20$ & $130 \pm 10$ & $90 \pm 4$ & $59 \pm 1$ \\
\hline
\end{tabular}
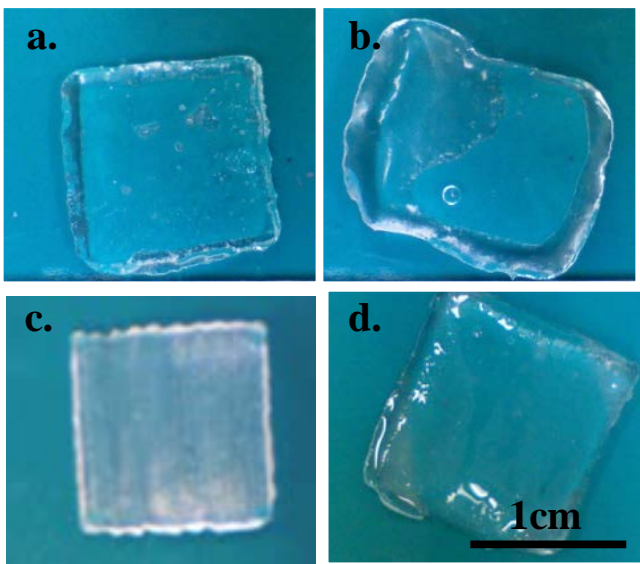

5 Fig. 5 Photographs of hydrogels printed from the 3\% w/v alginate solution a. as made, b. swollen in water, c. swollen in $0.1 \mathrm{M}$ Calcium chloride solution and d. swollen in $0.1 \mathrm{M}$ Calcium chloride solution and then swollen in water.

hydrogels normalised to their printed mass is shown in Figure 4a. 10 Immersion of the printed hydrogels in water produces a 3 - 5 fold increase in mass, increasing with increasing alginate content. In contrast, swelling in calcium chloride solution restricts the swelling to approximately a 1.2 fold increase of the printed mass and the water uptake is insensitive to the alginate content. The 15 free calcium ions likely increase the ionic cross linking of the alginate network and restrict the amount of water absorbed. Subsequent immersion of these calcium-treated hydrogels in water has an insignificant effect on the final swelling ratio.

The printed hydrogels immersed in water and without calcium 20 treatment have poor mechanical properties. Figure $4 \mathrm{~b}$ contains typical stress - strain curves for swollen hydrogels printed from the $3 \% \mathrm{w} / \mathrm{v}$ alginate solution and Table 3 contains a summary of their mechanical characteristics. In comparison to the as-printed hydrogels, the hydrogels swollen in water show a decrease in 25 Young's modulus from $66 \pm 5 \mathrm{kPa}$ to $23 \pm 3 \mathrm{kPa}$; a decrease tensile strength from $170 \pm 30 \mathrm{kPa}$ to $11 \pm 3 \mathrm{kPa}$ and the failure strain drops from $300 \pm 20 \%$ to $23 \pm 6 \%$ resulting in a loss to the work of extension from $260 \pm 3 \mathrm{~kJ} / \mathrm{m}^{3}$ to $1.2 \pm 0.1 \mathrm{~kJ} / \mathrm{m}^{3}$.

It is likely that swelling the as-printed alginate/acrylamide 30 hydrogels in calcium chloride solution increases the cross link density of the alginate polymer network. Calcium ions diffuse from solution into the hydrogel to form cross links with the guluronic acid units in the alginate. The mechanical characteristics of ionic - covalent entanglement hydrogels are 35 known to be sensitive to the cross link density of the ionic polymer network. ${ }^{17} \mathrm{~A}$ hydrogel printed from the $3 \% \mathrm{w} / \mathrm{v}$ alginate a.

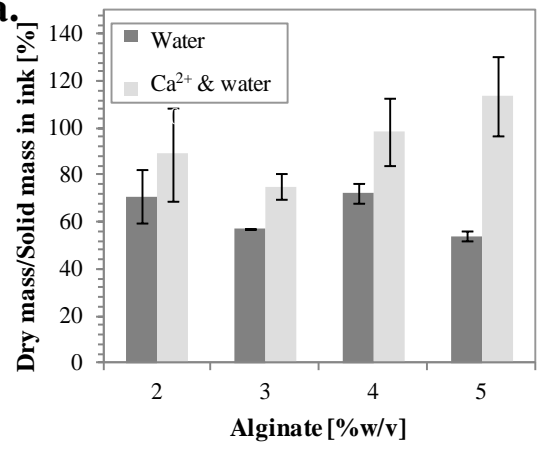

b.

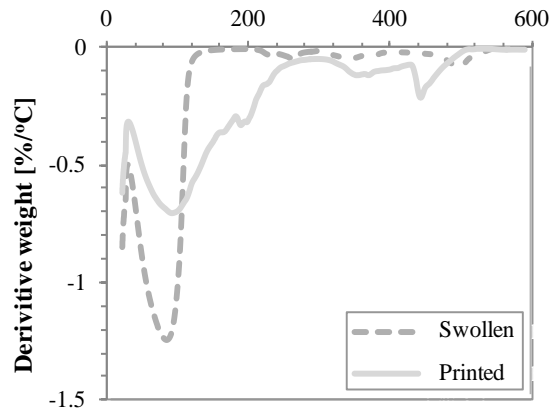

Fig. 6 a. Dry mass/solid mass in Ink of as made hydrogels printed with 2, 40 3, 4 and $5 \% \mathrm{w} / \mathrm{v}$ alginate solutions swollen in water and in $0.1 \mathrm{M}$ Calcium chloride solution and then swollen in water. b. TGA derivative of an as made hydrogel printed from the $3 \% \mathrm{w} / \mathrm{v}$ alginate solution before (solid line) and after swelling in $0.1 \mathrm{M}$ calcium chloride and water (broken line). The dry mass of gels that have been treated by swelling in water and by 45 swelling in $0.1 \mathrm{M}$ calcium chloride followed by swelling in water.

ink and swollen in $0.1 \mathrm{M}$ calcium chloride solution for $72 \mathrm{hr}$ shows a modulus increase from $66 \pm 5 \mathrm{kPa}$ (as printed) to $370 \pm$ $17 \mathrm{kPa}$ and the failure strain decreases from $300 \pm 22 \%$ to $89 \pm$ $20 \%$ because of the increased cross link density. When the 50 hydrogel is subsequently swollen in water a concentration gradient drives more water into the hydrogel which increases its volume. The dilution of elastically-active network strands creates a drop in modulus ${ }^{21}$ to $260 \pm 20 \mathrm{kPa}$ and in the work of extension to $59 \pm 1 \mathrm{~kJ} / \mathrm{m}^{3}$.

55 The effects of post-printing swelling on the shape of the printed objects are illustrated in Figure 5. Additional swelling must be compensated for in the design of models for printing to achieve the desired size and shape in the environment to which the hydrogel will be exposed during service. Figure $5 \mathrm{a}-\mathrm{d}$ is an 60 example of how the shape of a hydrogel printed with the $3 \% \mathrm{w} / \mathrm{v}$ alginate solution changes when it is swollen in water for $72 \mathrm{hr}$, $0.1 \mathrm{M}$ calcium chloride for $72 \mathrm{hr}$ and water after being immersed 
in the $0.1 \mathrm{M}$ calcium chloride for $72 \mathrm{hr}$ each. The dimensions of a hydrogel printed with the $3 \% \mathrm{w} / \mathrm{v}$ alginate solution swell to 161 $\pm 8 \%$ of its printed size. The printed hydrogel expands when in water because the osmotic pressure drives water into the hydrogel 5 to disperse the polymer network. The hydrogel deforms until equilibrium is reached between the osmotic pressure which expands the hydrogel and the hydrogels elasticity which tightens the polymer network. The large deformation to the hydrogel is due to its low cross link density.

10 Shape and size retention is improved for an alginate solution by first swelling in calcium chloride solution. Swelling an equivalent hydrogel printed with the $3 \% \mathrm{w} / \mathrm{v}$ alginate solution in a $0.1 \mathrm{M}$ calcium chloride solution will only expand to $106 \pm 6 \%$ of its initial dimensions. Subsequently swelling the hydrogel in 15 water increases its dimensions to $109 \pm 9 \%$ of its printed size. The additional cross links in the alginate network form the calcium ions increase the modulus of the hydrogels and reduce the swelling at equilibrium with water.

\section{Characterisation of Swollen Hydrogel Composition}

20 Finally, the composition of the hydrogels after equilibrium swelling was considered. It is known that unreacted monomer or un-cross linked chains can be removed from the as-prepared gel during swelling. The dry masses of the equilibrium swollen gels were determined after thoroughly drying the sample. Figure 6a 25 shows the dry mass of the swollen hydrogels as a ratio of the mass of polymer and monomer in the ink. The mass ratio of the hydrogels swollen in water is less than $100 \%$ which indicates a loss of solid content from the alginate network and / or loss of low molecular weight species not connected to the 30 polyacrylamide network. The alginate polymer network breaks down during the swelling process because the osmotic pressure drives the calcium ions out of the cross links. Break down of the polymer network structure allows alginate polymer chains to dissolve and diffuse out of the entangled hydrogel network. ${ }^{22}$

35 When swollen in calcium chloride additional cross links are produced so the alginate network does not break down and there is no significant change within the experimental error of the measurement between the dry mass and the solid mass in the ink.

Ethylene glycol was used as printing co-solvent in this study 40 since it was found difficult to print from aqueous inks due to the rapid evaporation of water during printing. Thermal gravimetric analysis was performed on hydrogels printed with the $3 \% \mathrm{w} / \mathrm{v}$ solution before and after swelling in calcium chloride and water to determine whether the ethylene glycol was retained in the 45 hydrogel after swelling. The temperature derivative weight plot in Figure $6 \mathrm{~b}$ for the as-printed hydrogel has a peak at $100^{\circ} \mathrm{C}$ attributed to evaporation of water and at $200{ }^{\circ} \mathrm{C}$ which may be attributed to the loss of ethylene glycol. No peak at $200{ }^{\circ} \mathrm{C}$ was observed for the equilibrium swollen hydrogel indicating that the 50 ethylene glycol had been removed from the hydrogel during swelling. The peaks above $200{ }^{\circ} \mathrm{C}$ are attributed to the breakdown of polymer.

\section{Conclusions}

An additive fabrication method was designed for processing ICE ${ }_{55}$ hydrogels into complex structures. The inks were composed of alginate biopolymer and a photo-curable acrylamide solution but the formulation can be extended to other chemistries. Control over pressure difference and temperature allows inks with a range of rheological properties to be extruded from the printer. By 60 proper control of these parameters, ICE hydrogels were printed that displayed outstanding mechanical strength with work of extension exceeding other types of printed hydrogels. Defects introduced during printing did restrict the mechanical strength of the printed ICE hydrogels in comparison to previously described ${ }_{65}$ cast ICE hydrogels and current work aims to reduce the incidence of such defects. Swelling in water immediately following printing had a detrimental effect on the alginate/acrylamide hydrogels because of partial dissolution of the alginate network. Postprinting immersion in a solution of calcium ions, however, can be 70 used as a post processing technique to help preserve the properties and dimensions of the hydrogels. It is expected that this UV-extrusion printing process can be implemented to construct mechanically robust hydrogel devices.

\section{Acknowledgements}

75 This work was supported by funding from the University of Wollongong, and Australian Research Council Centre of Excellence, Laureate Fellowships (G.G. Wallace) and Future Fellowship (M. in het Panhuis) and Professorial Fellowship (G.M. Spinks) Programs.

\section{${ }_{80}$ Notes and references}

${ }^{a}$ Intelligent Polymer Research Institute, ARC Centre of Excellence in Electromaterials Science, AIIM Facility, University of Wollongong, Wollongong, NSW 2522,Australia. Fax: 6124221 3114; Tel: 6124221 3010; E-mail: gspinks@uow.edu.au

$85^{b}$ School of Mechanical, Materials and Mechatronic Engineering, University of Wollongong, Wollongong, NSW 2522, Australia.

${ }^{c}$ Soft Materials Group, School of Chemistry, University of Wollongong, Wollongong, NSW 2522, Australia.E-mail: panhuis@uow.edu.au

90 1. N. Jones, Nature, 2012, 487, 22-23.

2. M. Y. Zhou, J. T. Xi and J. Q. Yan, Journal of Materials Processing Technology, 2004, 146, 396-402.

3. H. Fan, Y. Yu, A. Stump, S. T. Reed and et al., Nature, 2000, 405, 56-60.

95 4. C. Ferris, K. Gilmore, G. Wallace and M. Panhuis, Applied Microbiology and Biotechnology, 2013, 97, 4243-4258.

5. B. Derby, Science, 2012, 338, 921-926.

6. S. V. Murphy, A. Skardal and A. Atala, Journal of Biomedical Materials Research Part A, 2013, 101A, 272-284.

1007 7. T. Billiet, M. Vandenhaute, J. Schelfhout, S. Van Vlierberghe and P. Dubruel, Biomaterials, 2012, 33, 6020-6041.

8. F. P. W. Melchels, M. A. N. Domingos, T. J. Klein, J. Malda, P. J. Bartolo and D. W. Hutmacher, Progress in Polymer Science, 2012, 37, 1079-1104.

105 9. J. N. Hanson Shepherd, S. T. Parker, R. F. Shepherd, M. U. Gillette, J. A. Lewis and R. G. Nuzzo, Advanced Fuctional Materials, 2010, 21, 47-54.

10. T. Xu, C. Baicu, M. Aho, M. Zile and T. Boland, Biofabrication, 2009, 1, 035001-035006.

110 11. S. Naficy, H. R. Brown, J. M. Razal, G. M. Spinks and P. G. Whitten, Australian Journal of Chemistry, 2011, 64, 1007-1025.

12. Y. Okumura and K. Ito, Advanced Materials, 2001, 13, 485-487. 
13. R. Liu, S. Liang, X.-Z. Tang, D. Yan, X. Li and Z.-Z. Yu, Journal of Materials Chemistry, 2012, 22, 14160-14167.

14. M. A. Haque, T. Kurokawa, G. Kamita and J. P. Gong, Macromolecules, 2011, 44, 8916-8924.

5 15. S. E. Bakarich, G. C. Pidcock, P. Balding, L. Stevens, P. Calvert and M. in het Panhuis, Soft Matter, 2012, 8, 9985-9988.

16. L. Stevens, P. Calvert, G. G. Wallace and M. in het Panhuis, Soft Matter, 2013, 9, 3009-3012.

17. J.-Y. Sun, X. Zhao, W. R. K. Illeperuma, O. Chaudhuri, K. H. Oh, D.

10 J. Mooney, J. J. Vlassak and Z. Suo, Nature, 2012, 489, 133136.

18. R. A. Barry III, R. F. Shepherd, J. N. Hanson, R. G. Nuzzo, P. Wiltzius and J. A. Lewis, Advanced Materials, 2009, 21, 2407-2410.

15 19. S. Gupta, S. Goswami and A. Sinha, Biomedical Materials, 2012, 7, $1-8$.

20. T. C. Mezger, The rheology handbook, Vincentz Network, Hannover, Germany, 2006.

21. N. A. Peppas, P. Bures, W. Leobandung and H. Ichikawa, European

20 Journal of Pharmaceutics and Biopharmaceutics, 2000, 50, 27-46.

22. M. Kobašlija and D. T. McQuade, Biomacromolecules, 2006, 7, 2357-2361

25 